\title{
Festooned Appearance and Corticosteroid Treatment in Spontaneous Intracranial Hypotension
}

\author{
Yesim Sucullu Karadag ${ }^{1 *}$, Zehra Bozdogan ${ }^{1}$, Sule Bilen ${ }^{1}$, Esra Eruyar ${ }^{1}$, Neşe Oztekin ${ }^{1}$, \\ Gul Hatipoglu ${ }^{2}$ and Fikri $\mathbf{A k}^{1}$ \\ ${ }^{1}$ Ankara Numune Education and Research Hospital, Neurology Clinic, Ankara-Turkey \\ ${ }^{2}$ Ankara Numune Education and Research Hospital, Radiology Clinic, Ankara-Turkey
}

Received: October 10, 2014; Accepted: October 30, 2014; Published: November 07, 2014

*Corresponding author: Yesim Sucullu Karadag, Ankara Numune Egitim ve Arastirma Hastanesi Noroloji Klinigi Altindag, Ankara-Turkey, Tel: +903125084510; E-mail: yesimkaradag@yahoo.com

\section{Dear Editor,}

We report a successfully treated case of spontaneous intracranial hypotension $(\mathrm{SIH})$ with a festooned appearance in spinal magnetic resonance imaging (MRI).

The diagnostic triad of SIH consists of postural headache, low cerebrospinal fluid (CSF) pressure, and no history of lumbar puncture, trauma, infection, or surgery, and typical brain MRI findings [1]. In recent years, spinal MRI has begun to used to reveal the location of CSF leaks [2]. The headache of SIH typically resolves by conservative management such as hydration, analgesics and bed rest [1,2]. The epidural blood patch is considered the most effective treatment $[3,4]$. However, pharmacologic strategies may be considered before the blood patch. 4 Corticosteroids, caffeine, and theophylline have also been reported to be effective $[3,4]$.

A 37-year-old woman was admitted to our clinic with postural headache for two months. Her complaints completely resolved by lying down and were aggravated by sitting and standing up. The headache was throbbing and did not response to analgesics. The pain was localized in the occipitonuchal region at first then it resounded. Furthermore, the patient had blurred vision and vertigo for a month.

The patient was not taking any drugs except for paracetamol. There was no history of spinal surgery or intervention, trauma, or infection. No pathology was found in the physical and neurological examination.

Laboratory studies, erythrocyte sedimentation rate, C reactive protein, thyroid functions, autoantibodies, infectious panel (brucella, borrelia, tuberculosis, syphilis) were within normal ranges. The serum prolactin level was high 47.3 (4.7923.3) ng/mL. The opening pressure of CSF was $40 \mathrm{mmH}_{2} \mathrm{O}$. On CSF analysis, WBC cell count was $1 / \mathrm{mm}$ [3] and protein count was $53 \mathrm{mg} / \mathrm{dL}$. Glucose level was $49 \mathrm{mg} / \mathrm{dL}$.

Subdural hematoma was found in the cranial tomography. Brain MRI was consistent with diffuse pachymeningeal gadolinium enhancement, subdural collections, and decrease of ventricle volume. The pituitary MRI showed enlargement of the pituitary gland without adenoma. Also, engorgement of venous sinuses was seen in the MRI and MR venography.

The spinal MRI revealed large ventral and dorsal extradural fluid collection, thickened ventral epidural venous plexus and dural enhancement (Figure 1). Additionally, a festooned appearance of the epidural venous plexus was observed in the spine (Figure 1). There were no structural abnormalities that could cause CSF leakage.

The patient was treated with conservative therapy initially. Analgesics, hydration, caffeine, and bed rest were administered but her headache persisted. On the seventh day of hospitalization, oral prednisolone $1 \mathrm{mg} / \mathrm{kg} /$ day treatment was initiated, after which the patient's headache dramatically improved. Over the next three months, oral prednisolone was tapered off. Brain and spinal MRI were performed again after three months. Dural enhancement and subdural collection was markedly decreased but festooned appearance was persisted (Figures 2). The patient's headache completely improved.

SIH usually has a benign course; however, cases in which the patients have a reduced level of consciousness and subsequent stupor and coma have been reported [3].

The patient in the current presentation did not respond to conventional treatment. After the exclusion of any CSF leakage by the spinal MRI, corticosteroid therapy was initiated.

Corticosteroid therapy has a questionable value in the treatment of SIH. Although these drugs cause systemic fluid retention, any effect on CSF production or absorption has not been reported. ${ }^{2}$ On the other hand, corticosteroids could be recommended before epidural blood patches. ${ }^{4}$ Epidural patches are invasive methods and have complications such as back discomfort at the site of injection, paresthesia, radiculopathy, and lumbosacral meningismus [3]. A short course of corticosteroid treatment might be a rational approach before epidural blood patches. 

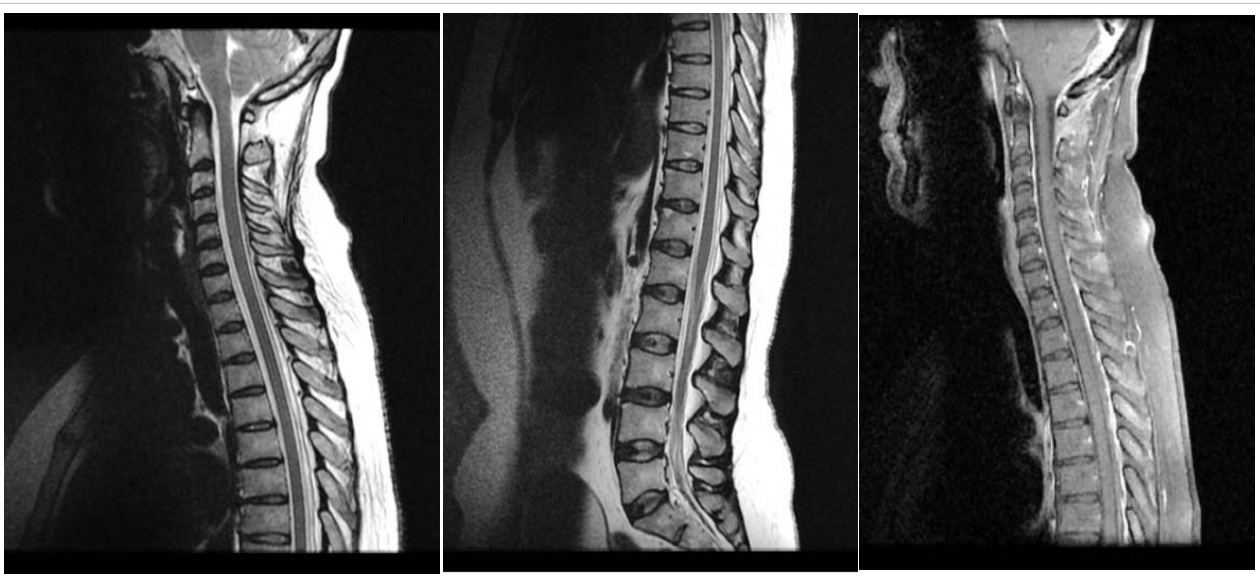

Figure 1: Sagittal T2 weighted images demonstrate epidural spinal collection which is isointense to cerebrospinal fluid through the spinal canal which doesn't enhance after gadolinium administration.
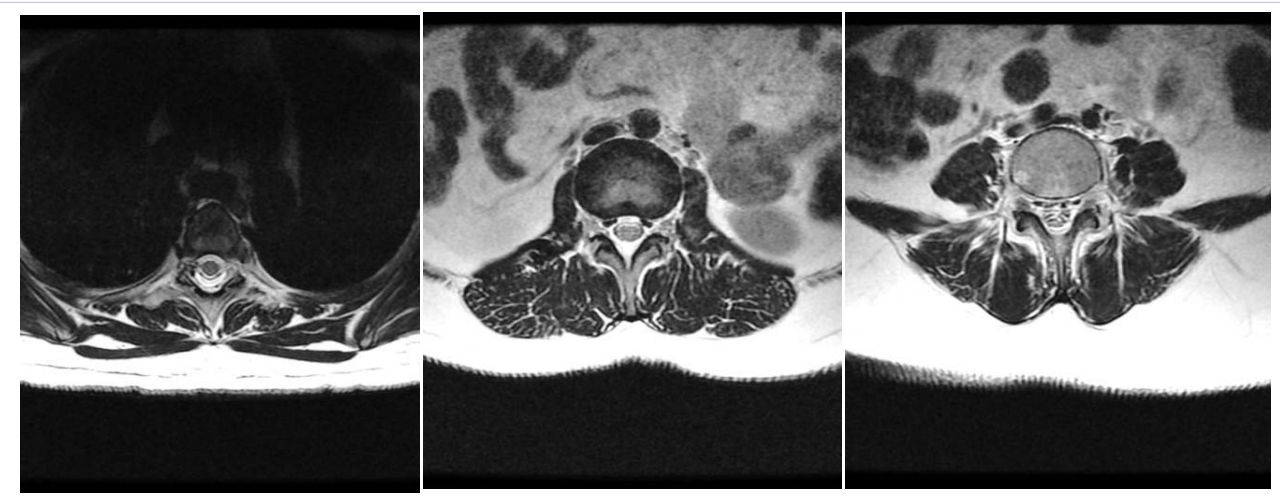

Figure 2: Axial T2 weighted image shows epidural collection (A), engorgement of the epidural venous structures (B) and festooned appearance (C).

Imaging methods have an important role in the diagnosis of SIH [5]. Although brain MRI is most frequently used, in some patients, classic intracranial findings may be absent [5]. As in the current patient, fluid collections, dilated epidural veins, dural enhancements are the spinal MR findings of SIH. The morphologic criterion used for SIH is the festooned appearance of the plexus in axial T2 weighted MRI. Favorable affects of treatments could be found in the control MRI after treatments [5].

In conclusion, spinal MRI provides additional information regarding the diagnosis and possible cause of SIH. Corticosteroid therapy might be an option, especially for patients resistant to conventional modalities before epidural blood patches.

\section{References}

1. Park E-S, Kim E. Spontaneous Intracranial Hypotension: Clinical
Presentation, Imaging Features and Treatment. J Korean Neurosurg Soc [Internet]. 2009 Jan 45(1):1-4. Doi: 10.3340/jkns.2009.45.1.1

2. Paldino M, Mogilner AY, Tenner MS. Intracranial hypotension syndrome: a comprehensive review. Neurosurg Focus. 2003 Dec 15; 15(6): ECP2.

3. Franzini A, Messina G, Nazzi V, Mea E, Leone M, Chiapparini L, et al. Spontaneous intracranial hypotension syndrome: a novel speculative physiopathological hypothesis and a novel patch method in a series of 28 consecutive patients. J Neurosurg. 2010 Feb;112(2): 300-306. Doi : 10.3171/2009.6.JNS09415

4. Hannerz J, Dahlgren G, Irested L, et al. Treatment of idiopathic intracranial hypotension: cervicothoracic and lumbal blood patch and peroral steroid treatment. Headache 2006; 46(3): 508-11.

5. Medina JH, Abrams K, Falcone S, Bhatia RG. Spinal imaging findings in spontaneous intracranial hypotension. AJR Am J Roentgenol. 2010 Aug; 195(2): 459-64. 